Nitrazepam was withdrawn in 38 children after a median of $1 \cdot 1$ years (range $0 \cdot 1-8 \cdot 1$ ). Maximum doses for these children averaged $12 \mathrm{mg} / \mathrm{day}$ (range $2-50$ ) for a median of $0 \cdot 9$ years (range $0 \cdot 1-6 \cdot 1$ ).

The 18 other children were still taking nitrazepam at the time of the study - that is, for a median of eight years (range 1-13). Maximum doses averaged $18 \mathrm{mg} /$ day (range 2-45) for a median of four years (range $0 \cdot 5-9 \cdot 5$ ). The longer the children remained on the drug the higher the dose often became. No change in pattern or number of seizures had been recorded in nine of these 18 children after the administration of nitrazepam.

Only two of the 38 children in whom nitrazepam was withdrawn had major seizures immediately after withdrawal. No worsening of seizures was recorded in the others and some appeared to improve. Eight children were reported to become more alert when the drug was withdrawn. Among the 56 children who were prescribed nitrazepam 15 were reported to be sleepy while receiving the drug and 17 to have deterioration in motor skills or ataxia. Four children stopped walking for periods of time, and three became unable to sit.

About $60 \%$ of children with tuberous sclerosis are estimated to be retarded. ${ }^{3}$ Psychosocial development is affected more than gross motor skill and most learn to walk. ${ }^{+}$We found highly significant associations between

No (\%) of children with tuberous sclerosis and myoclonic epilepsy whose first seizure was before 3 months $(n=21)$

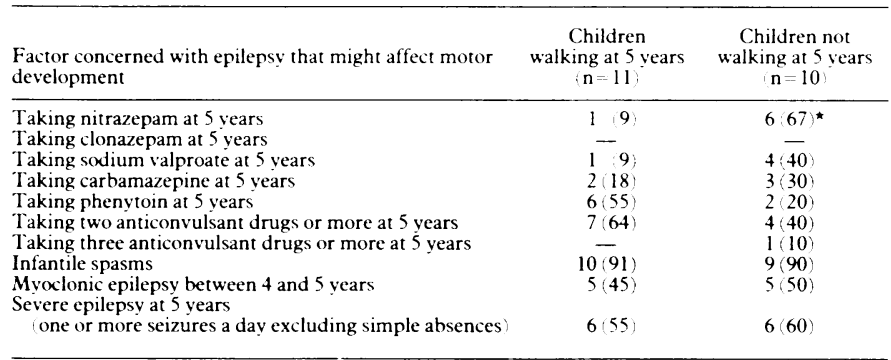

${ }^{\star} \mathrm{p}=0.02 ; \chi^{2}$ exact the inability to walk at the age of 5 and both the early onset of seizures and treatment with nitrazepam. The table concerns the 21 children who had a first seizure before 3 months. Epilepsy factors were compared for those able to walk and those unable to walk aged 5. Significantly more of those unable to walk were taking nitrazepam. No other factor differentiated the groups.

\section{Discussion}

Our findings suggest that nitrazepam has side effects that may be prejudicial to the motor and cognitive development of some of these already handicapped children. Furthermore, there are children other than those with tuberous sclerosis who have taken nitrazepam in high doses for many years.

We are aware of the grave difficulties facing doctors who care for children with refractory myoclonic epilepsy. For many such children nitrazepam is undoubtedly effective in achieving initial control of seizures, and for some it seems to remain effective for some time. For others, however, its long term efficacy as an anticonvulsant drug is less clear. We hope that our findings will alert doctors to evaluate their practice of prescribing with regard to the long term use of this drug in such children.

We thank all the doctors who let us see their hospital records and the parents who allowed us to seek the information from the start.

\section{References}

I Baruzzi A, Michelucci R, Tassinari CA. Benzodiazepines: nitrazepam. In: Woodbury DM, Penry JK, Pippenger CE, eds. Antiepileptic drugs. New York: Raven Press, 1982:753-69. 2 Browne TR, Penry JK. Benzodiazepines in the treatment of epilepsy. Epilepsia 1973;14:277-310. 3 Gomez. MR. Tuberous sclerosis. New York: Raven Press, 1979:16-20.

4 Hunt AM. Tuberous sclerosis: a survey of 97 cases. I. Seizures, pertussis immunisation and handicap. Dev Med Child Neurol 1983;25:434-5.

\title{
Normal variations in rate of albumin excretion and albumin to creatinine ratios in overnight and daytime urine collections in non-diabetic children
}

\author{
D J F ROWE, H BAGGA, P B BETTS
}

\begin{abstract}
Urine albumin excretion measured over consecutive weekends and on repeated first morning collections from normal children showed considerable variation both during the day and from day to day in each subject. The results emphasise the need for repeated measurement of albumin excretion in children to confirm the presence of persistent microalbuminuria.
\end{abstract}

\section{Introduction}

Urine albumin excretion above normal but Albustix test negative (so called "microalbuminuria") may predict diabetic nephropathy.' Intermittent microalbuminuria may also occur in children from exercise and postural changes, ${ }^{2}$ increasing the scatter of the reference range and the non-diabetic "false positive" rate. The use of timed overnight urine samples may reduce these potential errors. ${ }^{3}$

This study investigates the variations in daytime and overnight urine albumin excretion in individual non-diabetic children.

\section{Subjects and methods}

The 12 subjects studied (seven girls and five boys aged 5-17 years) were healthy children of members of staff. They voided immediately before going to bed, noting the time. Any night time urine was collected, as was the first morning sample, again noting the time, for 14 days. Every daytime urine sample over two weekends was also collected and its time noted, providing complete 48 hour collections for eight of the subjects. Each sample was weighed and frozen at $-20^{\circ} \mathrm{C}$.

\footnotetext{
Departments of Chemical Pathology and Paediatrics, The General Hospital, Southampton SO9 4XY

D J F ROWE, PHD, MRCPATH, ton grade biochemist

H BAGGA, fourth year medical student

P B BETTS, MD, MRCP, consultant paediatrician

Correspondence to: Dr Rowe.
} 
Albumin concentration was measured by immunoturbidimetry ${ }^{+}$and expressed as albumin excretion rates $(\mu \mathrm{g} / \mathrm{min})$ or as albumin to creatinine ratios $(\mathrm{mg} / \mathrm{mmol})$. Urine creatinine was measured using the Jaffé reaction.

Statistical analysis was by Student's $t$ test on log transformed data.

\section{Results}

The table shows the overnight and daytime albumin excretion rates and albumin to creatinine ratios recorded. Overnight albumin excretion rates were less than $10 \mu \mathrm{g} / \mathrm{min}$ except in one sample $(18 \mu \mathrm{g} / \mathrm{min})$. Daytime rates were significantly higher (up to $93 \mu \mathrm{g} / \mathrm{min}$ ). Overnight albumin to creatinine ratios were less than $4 \mathrm{mg} / \mathrm{mmol}$, whereas the daytime collections ranged up to $18 \mathrm{mg} / \mathrm{mmol}(t=5.3 ; \mathrm{p}<0.001)$. regular patterns of changes in albumin excretion might recur from one weekend to the next.

We assume that variations in albumin excretion occur to at least the same extent in diabetic children. Exercise related changes in albuminuria have been noted in other studies. ${ }^{2}$ We therefore emphasise that this pronounced variability in proteinuria should be taken into account when interpreting "microalbuminuria" data in diabetic patients. The results from single urine samples may be misinterpreted and persistent microalbuminuria should be confirmed on repeated samples, as our own studies (unpublished) and others ${ }^{1}$ show that intermittent microalbuminuria may be common. These episodes may coincide with worsening glycaemic control in some patients or be unrelated. We do not know whether this indicates an early stage in the progression through persistent

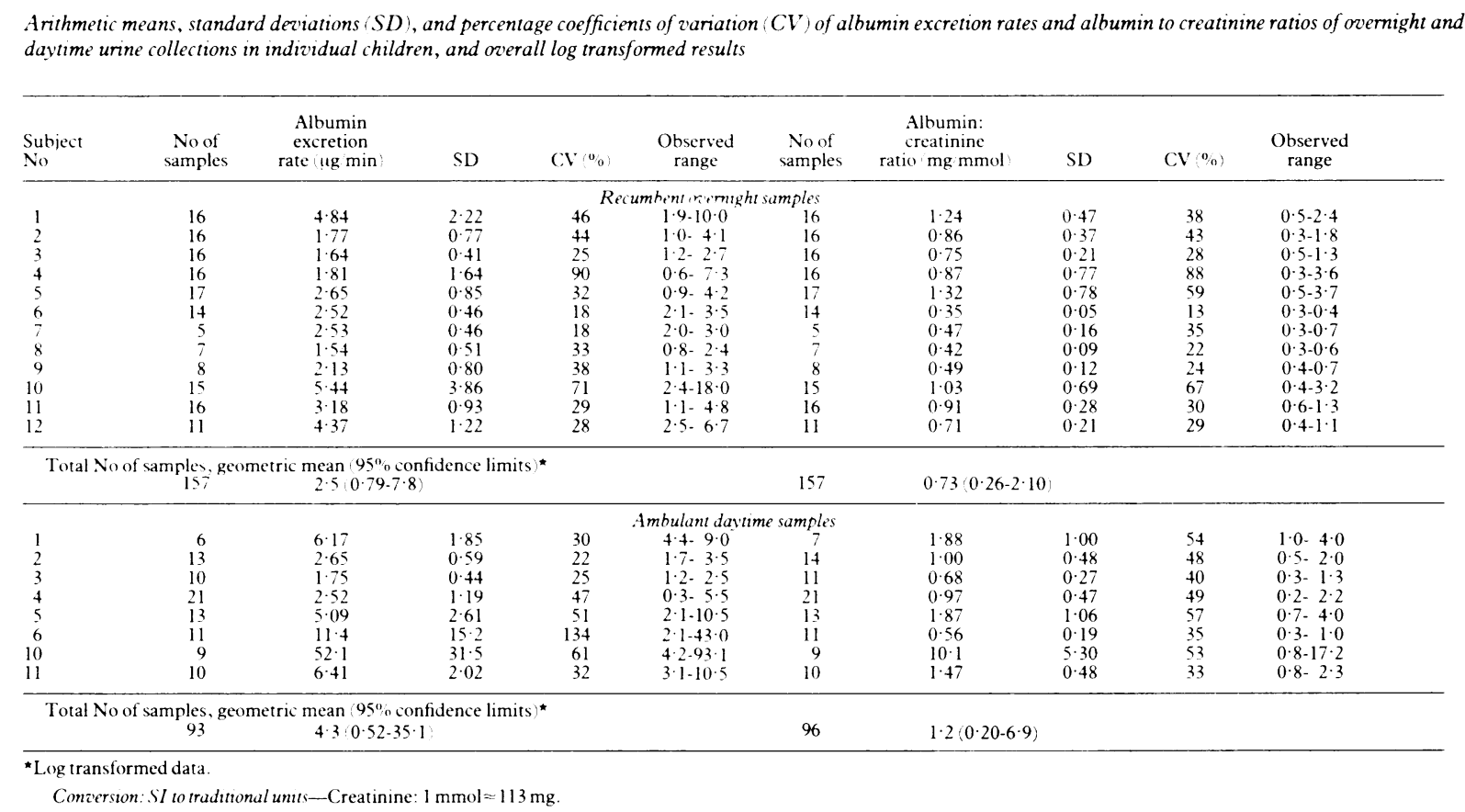

Daytime albumin excretion varied considerably both within and among subjects-for example, one (subject 10) excreted from 2 to $93 \mu \mathrm{g} / \mathrm{min}$ during the day. By contrast, her sibling (subject 11) excreted between 3 and $11 \mu \mathrm{g} / \mathrm{min}$ during the day. These variations did not relate to changes in posture or exercise.

Two of the boys showed a reproducible increase in albuminuria (two to three times higher than the mean of the remaining daytime samples) in the second sample each morning.

\section{Discussion}

This study shows that in children there is considerable normal variation in the overnight albumin excretion rate or albumin to creatinine ratio from day to day, agreeing with data from 24 hour collections in adults. ${ }^{1}$ These variations are unrelated to plasma albumin concentration, diuresis, or extracellular fluid volume and must therefore reflect changes in glomerular permeability or tubular reabsorption. Daytime fluctuations in excretion rates and albumin to creatinine ratios varied over 10 -fold during the day in some subjects. Regular changes in albumin excretion also occurred in some, presumably related to posture. Within any one subject microalbuminuria to clinical nephropathy. Persistent microalbuminuria, however, appears to predict clinical nephropathy. It must therefore be prudent to identify microalbuminuria early in the diabetic process and to establish whether it is intermittent or persistent, preferably using overnight timed samples.

We thank the children and their parents for their persistence in providing urine collections, Mrs Jane Mackinnon for expert secretarial help, and the chemical pathology staff for creatinine measurements.

\section{References}

1 Mathieson ER, Oxenboll D, Johansen K, Svendsen PA, Deckert T. Incipient nephropathy in type I (insulin dependent) diabetes. Diabetologia 1984;26:406-10.

2 Huttunen NP, Kaar ML, Puukka R, Akerblom HK. Exercise induced proteinuria in children and adolescents with type I (insulin dependent) diabetes. Diabetologia 1981;21:495-7.

3 Mogensen CE. Urinary albumin excretion in early and long-term juvenile diabetes. Scand $\mathcal{f}$ Clin Lab Invest 1971;28: 183-93.

4 Rowe DJF, Hayward M, Bagga H, Betts P. Effect of glycaemic control and duration of disease on overnight albumin excretion in diabetic children. BrMed f 1984;289:957-9.

5 Jerums G, Murray RML, Warwick K, Goodall I, Young VH. Remission and progression of true proteinuria in type I diabetes. Diabetic Nephropathy 1984;3:104-11.

(Accepted 2 fuly 1985) 